\title{
Retraction Note: Study on the expression specifications of geometrical products for function, design, manufacture and verification based on the improved GPS language
}

Limin Ma $\cdot$ Xiangqian Jiang $\cdot$ Jinxing Wang •

Zhengao Xu $\cdot$ Zhu Li

Published online: 6 October 2011

(C) Springer-Verlag London Limited 2011

Erratum to: Int J Adv Manuf Technol 32(9-10):990-998

DOI 10.1007/s00170-005-0395-0

This article has been retracted due to plagiarism.

The online version of the original article can be found at http://dx.doi. org/10.1007/s00170-005-0395-0 .

L. Ma $(\bowtie) \cdot$ X. Jiang $\cdot$ J. Wang $\cdot$ Z. Xu $\cdot$ Z. Li

School of Mechanical Engineering,

Huazhong University of Science and Technology (HUST),

Wuhan, Hubei 430074, People's Republic of China

e-mail: ly_mlm@163.com

X. Jiang

Centre for Precision Technologies, University of Huddersfield,

Huddersfield HD1 3DH, UK 